\title{
Non-statutory barriers and incentives to stakeholder participation in reducing water pollution: A South African case study
}

\author{
J Neysmith and M Dent* \\ University of KwaZulu-Natal, P/Bag X01, Scottsville 3209, South Africa
}

\begin{abstract}
A study was conducted in the Baynespruit, a small, highly-polluted, urban catchment in Pietermaritzburg, South Africa with 2 objectives: firstly, to develop an understanding of the views of stakeholders regarding the pollution problem and the relative importance of components of the problem; secondly, to identify and investigate non-statutory barriers and incentives to participation in multi-stakeholder processes aimed at integrated catchment management to create a healthy Baynespruit. The research methods embraced a number of different qualitative techniques, including a review of print media coverage, semi-structured interviews conducted with a cross-section of stakeholders, as well as participant and direct observation. The study identified the stakeholder groupings along with a number of non-statutory barriers and incentives to their participation in integrated activities to reduce pollution. These barriers and incentives were classed as economic, situational, developmental and socio-cultural in nature. For local residents, building a network of contacts and partnerships could address many of the economic, developmental and socio-cultural barriers they were found to face. Barriers to industry participation in pollution reduction were found to include problems such as a lack of consequences for polluting, and the feeling that it was 'not their problem'. Powerful economic and situational incentives, such as pressure from corporate customers and the public, seem to remain largely unexploited by stakeholders opposing pollution. A lack of resources in the form of time, staff and equipment, as well as unsuccessful past experiences which have created a reluctance to prosecute or release information, were found to be the major impediments preventing staff at government agencies and parastatals from motivating other stakeholders to participate.
\end{abstract}

Keywords: stakeholder, participation, water, management, incentives, barriers

\section{Introduction}

\section{Current state of the Baynespruit}

The Baynespruit originates in the Northdale and Raisethorpe neighbourhoods, flowing through the Willowton Industrial Area (WIA) and past small informal settlements and the Eastwood and Sobantu neighbourhoods before reaching its confluence with the uMsunduzi river, as shown in Fig. 1. It is blighted by chronic, severe, solid and liquid waste pollution, and its banks are clogged with invasive alien plants. Raw sewage flows into the stream as a result of sewer surcharges, where, due to heavy rain events or blockages, the sewer pipes which run along the stream overflow into the water course through breaks or manhole covers. Informal settlements, in which residents have no toilet facilities and thus often use the stream banks, also contribute to faecal pollution. Since 1990, E. coli levels in the Baynespruit have been above 5000 counts/100 $\mathrm{ml}$ more than $70 \%$ of the time, and have been recorded above 1 million/100 $\mathrm{ml}$ on a number of occasions (Umgeni Water, 2008). For comparison, the maximum safe level of E. coli for swimming is a mere 130 counts/100 $\mathrm{ml}$ (DWAF, 1996). Discharges of industrial effluent have resulted in fish kills, as well as blockages in the irrigation systems that some farmers in Sobantu use to water their vegetable gardens (Umgeni Water,

\footnotetext{
* To whom all correspondence should be addressed.

푱 +2783 4426360 ; fax: +2733 2606118 ; e-mail: dent@ukzn.ac.za

Received 30 October 2009; accepted in revised form 3 September 2010.
}

2002). Consequently, the stream also has very poor ecosystem health ratings, with a median South African Scoring System (SASS) score below 3, considered 'severely impacted' (Terry, 2008). In the most visible sign of pollution, household garbage tossed onto the floodplain or directly into the water from nearby residences chokes the Baynespruit, especially where it flows under bridges.

\section{Stakeholders}

In the area of the Baynespruit under study, the stakeholders were grouped into 3 categories: local residents and NGOs, industry representatives, and staff at statutory agencies and parastatals. The majority-Zulu community of Sobantu was chosen as the focus of the residential stakeholders group, in part because its residents live downstream of all the other factors contributing to solid and liquid waste pollution, but also because they make use of the Baynespruit's water for gardening and small-scale agriculture. Homes in Sobantu, founded in 1928, consist of 2 to 4 rooms; most have water and sewer connections, and are located along tarred roads (Msunduzi Municipality, n.d.). However, only about half of the total labour force is actually employed, with most residents reporting monthly incomes of ZAR1 600 or less (Statistics SA, 2001). Recently, the Sobantu Environmental and Agricultural Forum (SEAF), a coalition of residents, began collaborating with the Duzi-uMngeni Conservation Trust (DUCT), a non-profit organisation established in 2005 by recreational watercourse users. Through a variety of partnerships, the DUCT coordinates activities such as cleaning up litter, removing alien invasive 


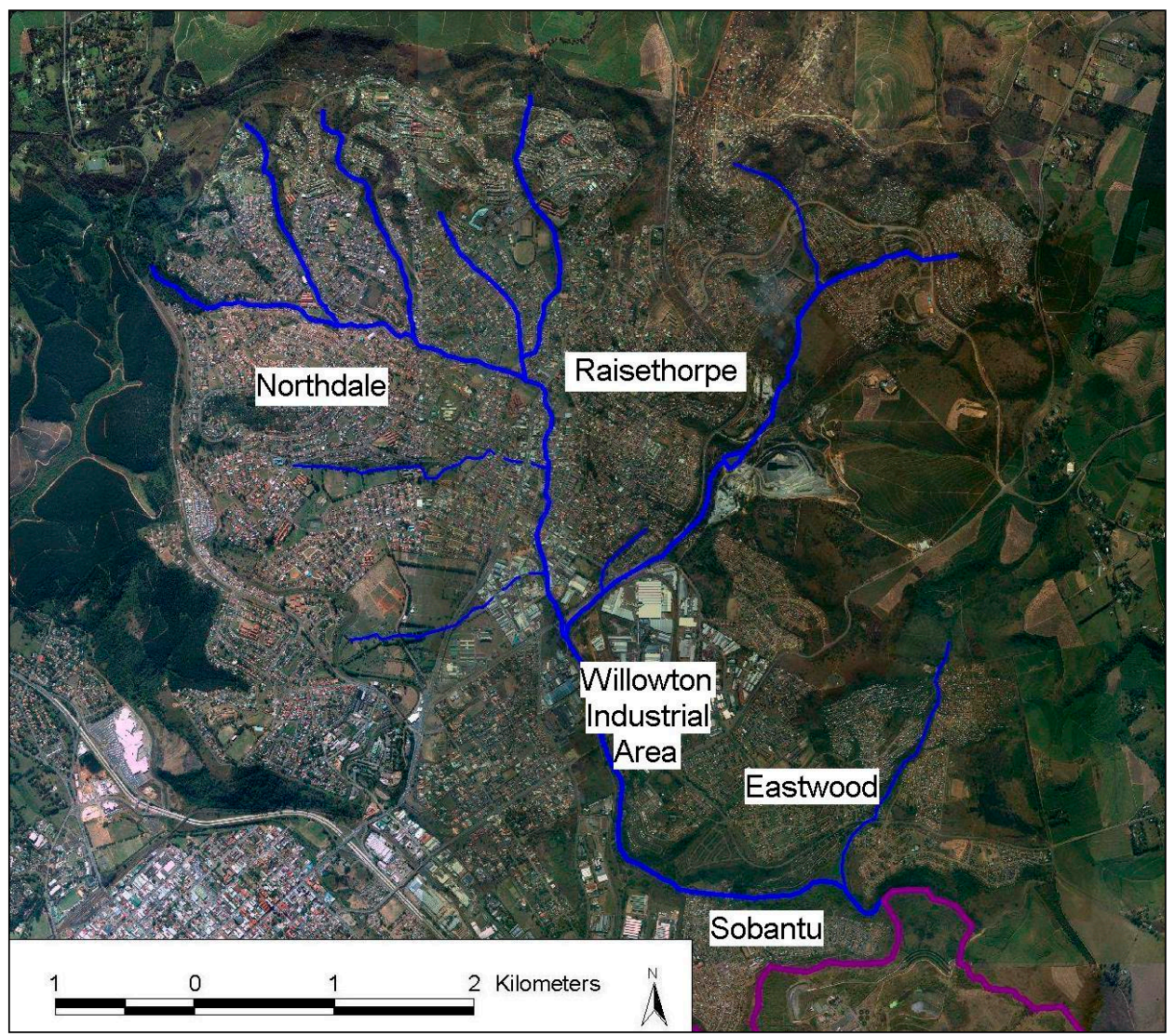

Figure 1

Map of the Baynespruit catchment (uMsunduzi River in purple)

Source: S. Terry, Umgeni Water (Aerial photo courtesy of Msunduzi Municipality, 2004)

species, planting trees, reducing soil erosion, and implementing education and awareness campaigns; as the main civil society organisation working on river health in the watershed of which the Baynespruit is a part, it was chosen to represent the NGO stakeholder group.

Industry representatives were chosen from among the factories located along the Baynespruit in the Willowton Industrial Area, which range in character from small independent operations to large subsidiaries of national or even multi-national companies. They manufacture a range of products, including carpets, chemicals, food and toilet paper, but in terms of water pollution the most contentious factories have historically been the 4 large edible oil, soap and candle manufacturers. The designated individuals representing this stakeholder group were typically either owners, or quality or operations managers. The final stakeholder group, representatives of statutory agencies and parastatals, included staff at the national Department of Water Affairs and Forestry (DWAF), which is the main policy coordination and regulatory body, charged with implementing and administering the National Water Act of 1998; the DWAF has responsibility for both water quantity and quality, including effluent discharges (De Coning and Sherwill, 2004). At the local level, managers and an elected official from Msunduzi Municipality (of which the City of Pietermaritzburg is a part) were included, as the Municipality is the main agency with jurisdiction over water-related powers and functions, including responsibility for sewer networks and industrial effluent bylaws. In addition, technical and scientific staff at
Umgeni Water, the regional water services provider, were considered to be part of this stakeholder group, as this parastatal conducts regular water quality testing and supports the municipality with regard to pollution monitoring and enforcement.

\section{Statement of the problem}

The current socio-ecological system, in which all Baynespruit stakeholders contribute to its pollution, whether through action or benign neglect, must somehow be altered in order to effect change. Previous targeted initiatives and statutory- and legally-based approaches such as state prosecution, operating within the existing power and information structures, have failed to achieve lasting results. One possible way to work toward reducing pollution problems is to involve all stakeholders in a more collaborative participatory process, that has the potential to enhance learning and hence lead to changes in their behaviour. Despite progressive policy, legislative and statutory frameworks for multistakeholder integrated water resource management being in place, the poor state of many rivers in South Africa indicates that stakeholder participation has either not been successfully implemented or has not led to decision-making and behavioural change that would encourage rehabilitation of the riparian system. Sustainable collective action may best be achieved through institutions such as catchment management agencies, which are still to be implemented in the area and which will address issues at a larger scale. CMAs may 
bring stronger collective support for marginalised communities, if they can leverage such support. A key element in any such participatory process, though, is the recognition and encouragement of incentives and the simultaneous removal or transcending of barriers to stakeholder participation that leads to feedback and learning and thereby behavioural change. To accomplish this as it relates to this case study, the perspectives of civil society, government and business groupings needed to be understood, with respect to the various factors that either encourage or discourage participation on the part of each stakeholder group:

- Economic

- Situational

- Developmental

- Socio-cultural

\section{Objective of the research}

The overall objective of the research was to determine how non-statutory barriers and incentives can influence stakeholder participation, using the issue of reducing water pollution in Pietermaritzburg's Baynespruit as a case study.

To achieve this, the specific objectives were to:

- Interpret past initiatives that have tried to address pollution in the Baynespruit, including the identification of lead stakeholder(s), goals, difficulties encountered and likely reasons for lack of success

- Understand stakeholders' views of the problem, by identifying the main stakeholders among industry, local residents, NGOs, and statutory agencies and parastatals, determining what they see as the major issues and their effects, and identifying the perceived importance of the problems

- Identify current barriers and incentives to participation, including economic, situational, developmental and sociocultural factors

This paper focuses on the third objective, while the first two objectives are given cursory attention.

\section{Research methods}

The study had two major aspects, namely, a literature review to provide the theoretical background and then fieldwork in the form of a case study. The literature review was designed to reveal and understand non-statutory incentives for, and barriers to, participation in stakeholder activities to enhance social learning that stimulates behavioural change that leads to reduced pollution.

Fieldwork took the form of a quasi-participatory case study. The research techniques employed included semi-structured interviews, documentation, participant observation and direct observation. The main measuring instrument was an interview consisting primarily of open-ended questions, and conducted to maintain the respondents' anonymity. The stakeholders who were interviewed were selected following a purposive sampling protocol, in which members of each stakeholder group were specifically targeted.

A pilot study was conducted to test and help refine the survey questions as a measuring instrument. While the existing questions were efficient at eliciting information about obvious barriers and incentives, mainly situational considerations such as logistics, they were not successful at drawing out underlying issues. Some of the questions were thus modified and/or added to, and additional follow-up questions were asked to elicit more implicit issues. The fact that the stakeholders interviewed varied widely in their demographic profiles was also taken into account. The interview questions were sometimes adapted to suit an individual, in order to convey '... equivalence of meaning' as suggested by Barriball and While (1994: 330). It must also be noted that responses may have been influenced by differences in race, religion and gender, for example, between the respondent and interviewer (Barriball and While, 1994; Monette et al., 2002).

Data analysis mainly involved the creation of a detailed descriptive narrative, as illustrated by Monette et al. (2002). Direct interpretation of the various sources of evidence and the recognition of patterns in the data, as described by Stake (1995) and Yin (1994), were used to achieve an understanding of the potential for various stakeholders to become fully involved in meaningful participation. According to the categorisation methods outlined by Monette et al. (2002), a combination of simple descriptive and more subjective interpretive codes was used to identify dominant themes in the data. The raw data were summarised to identify common elements within and among stakeholder groups, and barriers and incentives to participation were categorised as economic, situational, developmental, or socio-cultural.

\section{Discussion based on literature}

\section{Stakeholder participation}

Participation can be broadly described as an organised and equitable process which facilitates the exchange of thoughts and information (Appelstrand, 2002), or it may consist 'of any strategies employed by social actors to alter their life-world' (Warner, 2006: 17).

'Participation requires that stakeholders at all levels of the social structure have an impact on decisions' (Global Water Partnership, 2000: 16). In order for stakeholders to exert, or attempt to exert, control or influence over decisions and outcomes which concern them (Appelstrand, 2002; Gaventa and Valderrama, 1999; Irvin and Stansbury, 2004), they must be empowered. Power is a function of the relationships and resources which a person or an organisation can exert to achieve a desired outcome, in spite of opposition (Lozare, 1994). With regard to natural resource issues, power comes in many forms, including occupying positions of authority, possessing information, having financial means, being able to rally support, or enjoying privileged access (Borrini-Feyerabend et al., 2004). Many citizens do not hold any of these forms of power, and Arnstein's seminal 1969 paper, 'A ladder of citizen participation', thus categorised participation based on the degree to which participants were able to wield power and influence by participating.

At the top of her ladder, Arnstein (1969) designates 3 categories which consist of true citizen participation: partnership, delegated power and citizen control. One of the central themes at these levels is that citizens share in, or even control, the process. All affected stakeholders should thus become involved in the early stages of planning, long before decisionmaking occurs (Appelstrand, 2002; Involve, 2005). If barriers to participation can be overcome, successful multi-stakeholder processes can lead to 3 strategic outcomes identified by Warner (2006):

- 'Adaptive management', the development of a shared understanding leading to a joint future vision through group learning, experimentation and compromise 
- 'Democratisation and empowerment', the devolving of responsibilities to a representative forum which is not dominated by any one interest but gives voice to the concerns of marginalised groups in its discussions

- 'Alternative dispute resolution', in which conflict is managed through mediation and the ultimate goal is consensus (where possible) or at least an appreciation of the motivation underlying opposing views.

If conducted well, participation can lead to greater empowerment on the part of all stakeholders involved, be they individuals or organisations, as they develop increasing 'participatory competence' (Prestby et al., 1990) and assume positions of importance among fellow decision-makers (Irvin and Stansbury, 2004). Therefore, 'if participation is such an important ingredient for the development of individual empowerment, it is imperative that we understand what promotes and what hinders participation' (Prestby et al., 1990: 144).

\section{Barriers}

'The possibility for engagement cannot be taken as a given, even if mechanisms [for participation] are created' (Gaventa, 2004: 30). When certain stakeholder groups face barriers that prevent their participation, the outcome of a multi-stakeholder process is unlikely to be representative (Griffin, 1999) and may in fact be rejected by the stakeholders who were denied involvement. Removing or overcoming these barriers to participation should thus be of great importance. It is worth noting that while Prestby et al. (1990) make a distinction between barriers to participation and costs of participation, as this dissertation is concerned with long-term participation - which may be cut short by costs - it does not recognise costs as separate factors.

Widmer (1989) classifies barriers and incentives to participation in 4 categories:

- Material (tangible elements such as goods or services)

- Social (intangible elements such as status)

- Developmental (intangible personal elements such as acquiring knowledge or responsibilities)

- Ideological (intangible personal elements such as satisfaction or gratification).

For the purposes of this study, which will examine barriers and incentives to participation on the part of stakeholders ranging from large companies to individual citizens, 4 categories of barriers and incentives will be used:

- Economic (financial costs)

- Situational (e.g. time, physical conditions)

- Developmental (knowledge, skills and/or ability)

- Socio-cultural (e.g. power inequity, level of community organisation).

\section{Barriers for local residents and NGOs}

For ordinary citizens and members of NGOs, barriers to participation may be as basic as monetary, physical or time constraints (Griffin, 1999; Klandermans and Oegema, 1987; Wandersman et al., 1987). For disadvantaged individuals, one of the most basic barriers to participation is a lack of financial resources (Global Water Partnership, 2000) and/or prohibitive costs (Prestby et al., 1990), as well as a prioritisation of income-generation and daily family needs over attending meetings (Irvin and Stansbury, 2004; Wandersman et al., 1987).
Basic situational barriers include physical access problems for people with disabilities, child-care for parents of young children, or language barriers where translation is not feasible (Involve, 2005). Simply not having the time to devote to an intensive participatory process can also be an important factor (Negra, 1998). Other logistical/situational barriers to citizen and NGO participation include the scheduling of meetings (weekdays versus evenings or weekends), their length, and the location at which they are held (Griffin, 1999); factors such as a nearby meeting location can be especially important for certain participants (Irvin and Stansbury, 2004). As a result of these considerations, low-income earners and the self-employed are likely to be under-represented, while homemakers, retirees and public servants are often over-represented (Renn et al., 1993). Though more of a disincentive than a barrier, a participatory process that is long on talk but short on effective action may thus also discourage long-term participation (Berkes, 2002; Griffin, 1999: 512), as may dissatisfaction with progress achieved (Prestby et al., 1990; Wandersman et al., 1987).

Another significant barrier to citizen participation is developmental, in which individuals lack the specific knowledge and skills to understand and address the issues at hand. In interviews conducted with members of local Conservation Commissions in the American states of Vermont and New Hampshire, Negra (1998) encountered some participants who felt that new members needed background knowledge in order to have credibility, while others felt that experience could be developed through participation; in the former case, people without the necessary expertise may in fact be discouraged from participating. Even if they do participate, individuals without the relevant knowledge or skills may devalue their own contributions based on their perceived lack of expertise (Jonsson, 2005) or be overpowered by technical arguments or misinformation from 'professionals' (Arnstein, 1969; Gaventa and Valderrama, 1999).

Lack of power or decision-making authority can also act as a barrier to participation by ordinary citizens (Irvin and Stansbury, 2004). Wandersman et al. (1987) point out that scepticism about their ability to effect change is disproportionately found among the disadvantaged. The knowledge that key decisions are actually taken outside the participatory process, whether it is explicitly acknowledged at the outset or not, is a major disincentive to participation (Glew et al., 1995; Irvin and Stansbury, 2004; Prestby et al., 1990).

Other socio-cultural barriers can also play a role in limiting citizen participation. A lack of co-operation from authorities and peers (Wandersman et al., 1987), feeling unwelcome within the group (Prestby et al., 1990), or a desire to avoid conflict (Burke, 1968) may all discourage participation. Gaventa and Valderrama (1999) found that participation was positively correlated with the pre-existing level of citizen organisation (such as unions) in a Bolivian study, suggesting a degree of fluency in, and/or social encouragement of, participation. At the other end of the spectrum, complacency can be equally problematic (Mullen and Allison, 1999; Negra, 1998). In some cases, cultural norms may discourage or prevent participation by certain groups (Glew et al., 1995; Involve, 2005), while residents of certain regions may simply not have a history of active involvement (Mullen and Allison, 1999). When cultural differences exist among participants, even among individuals from the same area, communication barriers may arise (Servaes and Arnst, 1999). Factors such as class, ethnicity and gender can also play a role in creating the power imbalances discussed previously (Berkes, 2004). This effect can be subtle, 
influencing people's confidence and worldview, and thus the nature of their participation; listeners quickly form perceptions based, for example, on a speaker's accent or choice of words (Gaventa, 2004). For citizens and members of NGOs, therefore, situational, developmental and socio-cultural barriers appear to be of roughly equal importance, while economic barriers disproportionately affect the disadvantaged.

\section{Barriers for industry}

When it comes to pollution, "the rational man finds that his share of the cost of the wastes he discharges into the commons is less than the cost of purifying his wastes before releasing them' Hardin (1968: 1245). As long as a company perceives the costs of preventing pollution to be higher than the costs of not doing so, economic logic will dictate that it continues to pollute. Taking externalities into account, for example by instituting a 'polluter pay' system, can increase the costs of polluting and address this barrier.

Resistance to organisational change is another powerful barrier preventing participation on the part of industry. To undertake measures such as pollution prevention, a company must re-envision all its processes (Lober, 1998). Unfortunately, 'corporations do not widely view pollution prevention as an opportunity as its potential benefits are rarely recognised. Corporations also do not identify the factors that prevent or allow the marshaling of resources to exploit this potential opportunity' (Lober, 1998: 35). Perhaps an even more compelling barrier for a company that is resistant to change is the fact that participation usually requires more transparency related to information disclosure and independent assessment (Acutt, 2003).

Although more a disincentive than a barrier, firms may be reluctant to participate due to satisfaction with the status quo. As Afsah et al. (1997) point out, regulatory agencies tend to be lenient on firms with political clout or those facing economic difficulties, in the latter case for fear of being held responsible for job losses; they note that examples of such lax enforcement can be found in countries as diverse as Indonesia and the United States. If a company has managed to avoid compliance with existing laws and does not anticipate implementation of stricter legislation in the future, there is no incentive for it to participate.

Another barrier is the transparency required by participation, which reduces the opportunity for corruption (Wang et al., 2004) from which some may benefit. Finally, companies may simply view social and environmental concerns as the domain of government, not something which is part of a business mandate (Hamann and Acutt, 2003). For industry, then, participation is mainly limited by economic and situational barriers.

\section{Barriers for regulatory agencies and parastatals}

Three of the main barriers to initiating participatory processes for government and quasi-government agencies are essentially economic, in the form of time, direct costs and staff resources (Griffin, 1999). Participatory decision-making can be complex and time-consuming (Porto et al., 1999; Servaes and Arnst, 1999); insufficient financial resources, especially at the local level, may constrain provision of opportunities for citizen participation (Burke, 1968; Gaventa and Valderrama, 1999). Even in rich nations like Sweden, budget cuts have meant a move away from 'mutual learning' processes of late (Jonsson, 2005). It is far quicker and less expensive to allow an informed civil servant to take a decision than to engage in consultation, and extensive consultation can drain resources from other important work (Involve, 2005; Irvin and Stansbury, 2004). Burke (1968) therefore notes that agency-led participatory processes must take into account both the mandate and means of the lead department, to ensure that staff have the time and resources to identify community leaders and other key players, assist participants in developing an accurate and complete understanding of the issues, and facilitate meaningful participation. While individual staff members at regulatory agencies and parastatals may be willing to commit to a participatory process, they may be relatively powerless in promoting involvement unless legislation exists to provide for it, and there is political will to encourage it (Gaventa and Valderrama, 1999). While South Africa does not lack enabling legislation, with cooperative governance forming a pillar of the Constitution, the National Water Act (NWA) and the National Environmental Management Act, implementation of these principles has been slow.

The very fact that government agencies are themselves the decision-making bodies may be a disincentive to participation, as they retain the final authority regardless of whether or not they participate (Griffin, 1999). Participation can also bring greater scrutiny and pressure to increase transparency with regard to monitoring and enforcement activities (Afsah et al., 1997). Moreover, if instituting multi-stakeholder engagement will result in a government agency being required to cede some of its power, this can be an additional disincentive (Griffin, 1999). Elected officials and bureaucrats, especially at the local level, may view participatory decision-making as undermining their role (Involve, 2005; Servaes and Arnst, 1999).

Unfortunately, a flawed participatory process (for example, one unduly influenced by special interests) can lead to poor decision-making, but, having given up control, government agencies and politicians may have no choice but to acquiesce (Irvin and Stansbury, 2004). This problem can be compounded by the fact that while officials are accountable to the public for their actions, participants in multi-stakeholder processes generally are not (Griffin, 1999; Involve, 2005; Renn et al., 1993). This may increase government agency concerns about delegating authority to participants who are not perceived as having the necessary knowledge and experience to make decisions about technically-challenging issues (Involve, 2005). It must be noted that these caveats may not apply to the most formal multi-stakeholder bodies. For example, under the South African NWA, catchment management agencies are constituted as legally-accountable entities functioning under a governing board and holding prescribed powers and responsibilities (Thompson et al., 2001). Overall, economic, situational and to some extent socio-cultural barriers limit regulatory agency and parastatal participation.

\section{Incentives}

An incentive is something that motivates action, or in this case, participation. In their study of neighbourhood associations in New York City, Prestby et al. (1990) found that what they termed 'incentive management' was one of the most important factors determining groups' success or failure (which meant remaining active or becoming inactive). With regard to corporations, Afsah et al. (1997) note that 'reputational' incentives - how the company is perceived - can be important. For the purposes of this study, the same 4 categories used for barriers will be used to classify incentives: 
- Economic (financial or material benefits)

- Situational (e.g. convenience of location, improving conditions)

- Developmental (e.g. learning, networking)

- Socio-cultural (e.g. influencing decisions, recognition)

\section{Incentives for local residents and NGOs}

With respect to citizens and NGO members, the data on material incentives is unclear (Klandermans and Oegema, 1987), but they appear to be relatively unimportant (Prestby et al., 1990; Wandersman et al., 1987). However, it should be noted that where the alternative is litigation or other legal action, engaging in a participatory process is obviously advantageous in terms of cost avoidance. Basic logistical incentives include limiting the number and length of meetings, providing child care, and offering safe transportation to and from meetings (Prestby et al., 1990). Other situational incentives are related to perception. Stakeholders are far more likely to be motivated to participate if they recognise the existence of a problem and are sufficiently concerned about it to want to effect change (Burke, 1968; Mullen and Allison, 1999).

One of the advantages to citizens of involving themselves in multi-stakeholder processes is gaining new knowledge, skills and experience - including developing their ability to advocate effectively (Irvin and Stansbury, 2004; Prestby et al., 1990). Developmental incentives can work both ways, though. Some stakeholders are actually more inclined to participate if they feel they have knowledge and expertise to contribute (Negra, 1998), whether this be through formal education and training, or personal - and often local - experience (Involve, 2005).

Perhaps the most important factors in determining an individual's willingness to participate are socio-cultural. Wandersman et al. (1987) found that people with strong roots in a community, who had lived there for a considerable length of time or planned to stay in the area, were more likely to participate in neighbourhood associations. One of the main incentives for citizen and NGO participants is the perceived ability to make a difference through participation (Burke, 1968; Mullen and Allison, 1999). This usually takes the form of having some influence over the decision-making process (Irvin and Stansbury, 2004) which will affect their lives in the future. Mirroring the disincentive to long-term participation found when stakeholders were dissatisfied with achievements made, progress and accomplishments were found to be an incentive for continued involvement (Burke, 1968; Wandersman et al., 1987). Participating in a multi-stakeholder forum is also likely to result in citizens forming relationships with influential individuals, contacts which may prove valuable. Especially for marginalised individuals, such interaction can be empowering (Irvin and Stansbury, 2004). A number of authors highlight the importance of providing not just collective but also personal (selective) incentives (Klandermans and Oegema, 1987; Prestby et al., 1990), so that individuals have some motivation to participate themselves, rather than assuming someone else will make the effort. However, many people participate initially simply due to a personal contact and continue because they appreciate the social interaction and recognition, while others are motivated by the desire to contribute to their communities (Negra, 1998; Prestby et al., 1990). Other social incentives include a welcoming environment at meetings, the opportunity for social interaction (Prestby et al., 1990), and a sense of group identity (Burke, 1968). While situational and developmental incentives are important for citizens and members of NGOs, then, sociocultural incentives play a greater role.

\section{Incentives for industry}

There is no question that for industrial stakeholders, the threat of financial penalties in the form of either discharge fees or fines and legal costs associated with legislative enforcement can act as powerful incentives to undertake pollution reduction programmes (Bansal and Roth, 2000; Triana and Ortolano, 2005). Incentives may also be provided by regulators in the form of subsidies, or technical information and assistance (Khanna, 2001).

One may rightly question how such measures undertaken by industries relate to participation in multi-stakeholder fora; for companies though, receptiveness to such initiatives is all part of what Bansal and Roth (2000) term 'corporate ecological responsiveness'. In South Africa, for example, only $21 \%$ of the 100 largest companies by revenue produce a corporate responsibility strategy for public consumption (KPMG, 2008). Despite this low figure there is growing anecdotal evidence that these large companies are beginning to look down their supply chain to ensure that they are not tainted by the environmental and social behaviour of their suppliers. These most advanced companies are also the most likely to work cooperatively with other stakeholders and to undertake commitments such as the Voluntary Environmental Agreements (VEAs) discussed by Buysse and Verbeke (2003).

For firms that do not take a proactive stance, public pressure and regulators that make environmental performance information available to consumers can be very powerful motivators (Afsah et al., 1997; Khanna, 2001; Kraemer et al., 2001; Wang et al., 2004; Wheeler, 1999). Where civil society is particularly active, NGOs may use information disclosure not just to target companies themselves, but also their clients and suppliers (Buysse and Verbeke, 2003). Conversely, when corporations are recognised for their achievements, they benefit not only from good external publicity, but also from employee validation and motivation (Triana and Ortolano, 2005; Senge et al., 2005; Senge et al., 2008). This incentive depends heavily on the importance of reputation, though: an obscure firm may be relatively immune, while one in the public eye, or a company supplying such a firm, may experience significant market gains or losses based on pollution abatement or other environmental performance measures (Afsah et al., 1997). Despite the lack of consensus among experts on the importance of customers, shareholders and the local community in influencing corporate environmental policies (Buysse and Verbeke, 2003), such use of public pressure and market forces has recently become a major factor in spurring corporate participation. While local communities may exert social pressure, consumers and investors may apply financial pressure, not only by boycotting known polluters and their products (Buysse and Verbeke, 2003; Wang et al., 2004), but also by granting preference to corporations given public recognition of environmental achievements (Buysse and Verbeke, 2003; Khanna, 2001).

'Reputational' factors can motivate companies to collaborate in good faith as part of multi-stakeholders processes (Afsah et al., 1997). On the other hand, Hamann and Acutt (2003) caution that some firms may be motivated to participate in multi-stakeholder processes only to enhance their image, attempt to control the process, or both. Therefore, while some industry incentives may involve situational and socio-cultural elements, the majority are primarily economic. 


\section{Incentives for regulatory agencies and parastatals}

Government and quasi-government agencies are tasked with upholding and complying with legislation which enshrines pollution prevention. Involving stakeholders in the decisionmaking process may allow these agencies to save costs by reducing confrontational enforcement activities (Jonsson, 2005; Mullen and Allison, 1999) and avoiding expensive litigation (Irvin and Stansbury, 2004; Jonsson, 2005).

Government agencies and parastatals may view participatory processes as a method by which to inform and educate the public and other stakeholders, and it is true that such processes can focus public attention and broaden awareness (Jonsson, 2005). Another incentive for regulators is that participatory processes lead to decisions that are better understood and seen as more legitimate by the public (Appelstrand, 2002; Carnes et al., 1998; Irvin and Stansbury, 2004). Involving all stakeholders is not only more likely to result in broad-based support for decisions, but should also reduce dysfunctional conflict among stakeholders, often an equally desirable outcome for regulatory agencies (Griffin, 1999; Jonsson, 2005). While the ceding of decision-making power was discussed as a barrier to government agency and parastatal participation, the reverse of this argument is that it allows agencies to avoid making, and taking the blame for, controversial decisions (Griffin, 1999).

\section{Summary of key findings}

\section{Pollution and remediation efforts in the Baynespruit}

A survey of articles written about water quality issues in the local Pietermaritzburg newspapers indicates that industrial effluent polluting the Baynespruit has been a problem for two decades. Several large oil and wax factories, in particular, have been charged numerous times by both national and municipal authorities over the years, but prosecution has proven unsuccessful. This has also been the case with regulatory threats made by the Department of Water Affairs and Forestry to stimulate action on the part of the local Msunduzi Municipality to address the ongoing sewage pollution. Citizen-led pressure was first brought to bear in 2001 by a group of Sobantu residents focused on environmental issues. Their presentation of a petition to the mayor of Pietermaritzburg and local Chamber of Commerce and Industry was followed by the establishment of the Baynespruit Task Team (BTT), consisting of representatives from industry, the municipality and residents of Sobantu. The BTT was successful in eliminating industrial discharges for a period of several months, but with the problem 'solved' the pressure relented, the Task Team became inactive, and discharges of industrial effluent into the Baynespruit soon resumed. Though stakeholders engaged one another in communication, the BTT did not include any redistribution of power and was thus not a truly participatory process, with residents of Sobantu remaining marginalised. Nonetheless, the short-term success of the increased monitoring and response to pollution incidents by regulatory agencies and parastatals during the period in which the BTT was active indicates that this is a key component in motivating industry.

\section{Stakeholders' views of the problem}

To determine how the diverse stakeholder groups would approach a multi-stakeholder process, it was critical to begin by understanding what they saw as the major pollution issues and their effects, and the importance they attached to these problems. In general, respondents identified industrial pollution as being the most significant problem, and the impact of pollution on human health as the greatest concern. Otherwise there was substantial variation among, though not as much within, the stakeholder groups. Local residents and NGO members, as well as regulatory agency and parastatal staff, both placed greater value on clean and healthy water courses than did industry representatives. With regard to responsibility, attitudes varied widely among stakeholders. Agency staff largely felt a duty to contribute as much as possible to finding solutions, while local residents tended to view themselves as victims of externally-generated pollution, though many were willing to accept some responsibility for assisting with pollution reduction. On the other hand, industrial representatives generally felt that the problems should be addressed by local government.

Local residents and NGO representatives who interacted most closely with the Baynespruit felt the effects of pollution most keenly; they also had detailed knowledge of the pollution issues, recognising industries as a major cause of water pollution, followed by sewage contamination and the dumping of garbage. In addition to human health concerns arising from the use of stream water to irrigate residents' vegetable plots, they identified a loss of food security (fishing and agriculture) as well as recreational opportunities for paddlers and local children, the latter primarily for swimming. As for how they would begin addressing the pollution problems, most residents expressed a preference for some kind of dialogue among all stakeholders, backed up by close monitoring - in large part because this is the only approach that has shown some success.

Industry representatives, meanwhile, maintained that their firms derived no benefit from the Baynespruit, despite the fact that all sites had stormwater drains which emptied into the stream and many employed people who lived downstream. Most did express general concern for the state of the stream, from an ecological as well as a human health perspective. In general, industry representatives identified industrial effluent as the main problem affecting the Baynespruit, followed by garbage; only one respondent mentioned sewage as a concern. The most common suggestions they made regarding how to address the pollution problems involved companies taking responsibility for their effluent, along with more stringent enforcement of the law, as well as education for residents on pollution issues.

Regulatory agency and parastatal staff had the most holistic view of the water course as part of larger ecological and human systems. All respondents expressed considerable concern for the pollution in the Baynespruit, identifying illegal industrial discharges as the most problematic contributing factor, but also pointed the finger at residential sources of pollution, lack of service provision to settlements, ageing sewer infrastructure, population increases and greater population density, and misuse of the sewer network resulting in blockages and surcharges. Human health was chief among the impacts recognised, but respondents also mentioned environmental health, erosion, damage to infrastructure, pests, unpleasant smells, and problems for downstream users both small and large. Most respondents recommended education and awareness-raising for residents, and some felt that industry should also be approached in this way. A number of respondents said that more resources would be required, whether to maintain and replace infrastructure, increase monitoring, carry out community capacity-building or take legal action. 


\section{Barriers to participation}

For the majority of stakeholders in all groups, economic barriers were significant in preventing them from working toward a reduction in pollution. For local residents, financial barriers included lack of funds for transport and supplies, as well as an expectation of reward for volunteer work. For the NGO representatives, the main problem was lack of staff time, which, along with equipment, was also a barrier to regulatory agencies and parastatals; some respondents in the latter group also mentioned a lack of support from management. For industries, evidence from other respondents indicated that pollution reduction was often too costly to warrant the required expenditure. The costs of pollution must therefore be raised to ensure full cost accounting, for example through the instituting of a tradable permit system.

When it came to situational barriers, there was general agreement among stakeholders that a participatory process which was not proactive and collaborative, or was not making progress, would discourage participation. In addition, logistics such as the timing and location of meetings were issues raised by a number of respondents across all stakeholder groups. Given its constitutional and legislative basis in South Africa, regulatory agency and parastatal staff members had surprisingly little experience with cooperative governance. Poor cooperation among agencies, coupled with a lack of confidence in data collection and unsuccessful attempts at litigation, have all created mixed situational and socio-cultural barriers to government and parastatal effectiveness. Both local residents and some industry representatives criticised the lack of monitoring and enforcement by authorities, but, with the exception of the NGO representative, they seemed unable to see how they could take action themselves to transcend this barrier. While representatives from industry responded positively to the idea of a multi-stakeholder forum, very few actually attended the Baynespruit Conservancy's first meeting, perhaps due to their low prioritisation of the issue, or a desire to avoid taking responsibility for current conditions or for making future commitments. Another barrier to polluters was the removal of potential motivating factors for change, such as the ongoing lack of enforcement by regulatory agencies, or even corruption, which was alluded to by several respondents.

Developmental barriers, in the form of a lack of skills and knowledge, were apparently restricted to local residents. A lack of empowerment, combined with learned dependency, was a major factor, though cultural elements also seemed to come into play. Residents either were not fully cognizant of the options available to them to bring pressure to bear, or were not taking full advantage of them. This was also a problem to some extent for regulatory agencies and parastatals, who could take a more creative approach to information disclosure, for example, by recognising those companies that are in compliance and allowing the logical conclusions to be drawn about other firms.

Socio-cultural barriers were also greatest among local residents. It gradually became clear that building contacts, networks and partnerships was key to overcoming many of the barriers they faced. Being 'connected' can bring, for example, knowledge of and access to funding sources, education and training resources (especially those not provided by government), as well as opportunities to build advocacy skills and become informed about the many strategies to raise awareness and bring pressure to bear. Unfortunately, residents seemed to be waiting for another stakeholder to lead this process, and it is hoped that a partnership with the Dusi-uMngeni Conservation
Trust (DUCT), a local NGO, will help them overcome many of the barriers they currently face. If citizens are unimpeded in taking action, this could in turn bring about the removal of some of the 'artificial' barriers, such as the lack of an enforcement threat or satisfaction with the status quo, holding other stakeholders back (particularly those in industry, but also in regulatory agencies and parastatals) and preventing what would otherwise be powerful incentives to reduce pollution from being effective.

\section{Incentives to participate}

As with barriers to participation in pollution reduction, economic incentives played a role for all stakeholder groups. For local residents, this incentive took the form of employment or material goods. Situational elements came into play for regulatory agency and parastatal staff, for whom incentives consisted mainly of either citizen assistance with monitoring, or avoidance of remediation costs by cooperating with industry to reduce pollution. For most industry respondents, economic incentives were very important, with companies primarily motivated by corporate customers' requirements or achieving certification standards set by industry or government, such as ISO 14000 or BBBEE status. Publicity, either positive or negative, was also noted as a factor which could act as an economic incentive.

The primary situational incentive for local residents and NGOs was the opportunity to contribute to bettering the community's - and their own - well-being. Interestingly, regulatory agency and parastatal staff also felt personally motivated to improve the situation, and were generally eager to share information if this could assist the process. Situational incentives for industry included employees' health (for those who live downstream) and general morale, though the importance of this incentive varied substantially among respondents.

As was the case with barriers, developmental incentives were apparently limited to local residents who wished to learn or contribute knowledge and skills. The most important incentives for this stakeholder group, though, were socio-cultural. Chief among them was the chance to communicate with other stakeholders, and potentially generate solutions together. However, an important secondary incentive, whose potential residents do not seem to have fully recognised, is the opportunity to make contacts, gain access to information and meet well-connected or influential individuals. For industry, a potential socio-cultural incentive to participate would be an appeal to those companies who practise corporate responsibility, though at the moment their focus is more social than environmental.

Some incentives were evidently not playing as strong a role as they could have been. For example, the fact that regulatory agencies have largely abdicated their enforcement duties meant that avoiding the costs of prosecution was no longer an incentive for industry. While all respondents described the role of situational incentives, the dearth of actual industry participation when the opportunity arose indicates that improving the current situation is in fact not a priority for them. However, a number of incentives were nonetheless identified among stakeholders in each category, and, along with the removal of artificial barriers, it should be possible to translate these incentives into progress.

\section{Conclusions}

Whilst cautioning that we do not wish to draw generalisable insights from a single case, it was concluded in this study that 
non-statutory barriers and incentives do indeed have the potential to influence multi-stakeholder participation in reducing water pollution. However, as outlined in the preceding sections, a number of changes must be made for the incentives to be maximised and for stakeholders to be able to transcend the barriers they face and engage each other in the future. Increasing the influence of incentives and reducing the strength of barriers could include strategies such as making use of the ability of monitoring and public pressure to stimulate industrial and municipal action, as well as exploiting the potential for better coordination and more effective leveraging of power, especially on the part of community members. In addition, though developmental barriers and incentives appeared to play a role only for local residents, all stakeholders would benefit from greater information and awareness, something that should take place naturally as part of the participatory learning process. This should allow all parties to begin thinking beyond their immediate interests; some stakeholders will have farther to go in broadening their viewpoints than others.

Active participation by all stakeholders does not by itself guarantee the success of a given participatory process. Factors such as leadership and facilitation, the decision-making process (majority, consensus, etc.), stakeholder continuity, and funding support all play important roles in determining success or failure (Griffin, 1999; Irvin and Stansbury, 2004). Creating what Prestby et al. (1990: 144) called an 'empowering organisation', which can 'provide opportunities for individual participants to develop skills, gain control, and identify with others' in order to achieve the goal of pollution reduction will undoubtedly require time, resources and effort. At the moment there is a decided lack of vision, much less a shared sense of purpose, surrounding the future of the Baynespruit: local residents picture a return to the past before pollution degraded the stream, regulatory agencies and parastatals want something done to clean things up, and industry seems to consider improved social conditions such as housing and service provision as the answer.

\section{Recommendations}

Based on the key findings of the study and the conclusions drawn, a number of recommendations may be made. With regard to each stakeholder group, the possibilities available to them to work toward the goal of participatory pollution reduction in the Baynespruit are highlighted. In addition, changes that would have improved the research methodology are made, along with suggestions for further research.

\section{Local residents and NGOs}

Local residents do not appear to be taking full advantage of the potential public and political pressure they could bring to bear by developing their network of contacts. By moving beyond, for example, the local Ward Committee or partnerships developed at the municipal level, they could gain access to more powerful leverage.

Another option that residents could use is Community Environmental Monitoring (CEM), in which citizens collect data about plants and animals, water quality, air pollutants or other elements of the environment. CEM is often undertaken for advocacy purposes, and such tactics are already being used in South Africa. For example, citizen-led air quality monitoring in South Durban and Rustenburg is coordinated through the Pietermaritzburg-based GroundWork.

\section{Industry}

With a couple of exceptions, the pollution affecting the Baynespruit was not something about which industry representatives were well-informed or even particularly concerned. Most companies do not see themselves and their stormwater outfalls as part of the larger socio-economic system of which the Baynespruit is a part, but this situation may well change if all stakeholders are forced to consider their use of and impacts on water resources through a formal structure such as a catchment management agency. This framework will also eliminate some of the artificial barriers identified in this research, such as the lack of an enforcement threat, as discussions and decisions will take place in an open, transparent forum, rather than directly between industry and the regulatory agency - what Molle et al. (2008) termed the 'governance black box'. Moreover, this public focus may well result in the increased market pressure for pollution abatement measures identified by Afsah et al. (1997), as the links between large corporate customers and their poorly-performing suppliers are made public. In the meantime, companies with good records could create goodwill (and likely good publicity) by participating alongside fellow stakeholders in working toward pollution reduction.

\section{Regulatory agencies and parastatals}

Staff at regulatory agencies and parastatals are aware of the causes and effects of the pollution problems along the Baynespruit. Where resources are lacking to carry out adequate monitoring and enforcement, they could form partnerships with civil society, both to focus their resources and increase the pressure on management and elected officials to address the issues (though this latter strategy is obviously sensitive). More importantly, these agencies control the flow of information. The establishment of the Toxic Release Inventory in the United States, through which companies' reported discharges of air pollutants were made publicly available, resulted in a $40 \%$ reduction in emissions within 4 years; this positive 'race for the bottom' was inspired not by any legislative or economic inducements, merely by the worst polluters' desire to present a better image to the communities in which they operated (Meadows, 1999). If even this mechanism is not possible without the threat of libel, the opposite tactic of releasing positive information - for example, on those industries which are in compliance with their trade effluent permits - would nonetheless generate public scrutiny.

\section{Improvements to the methodology}

A number of authors have pointed to the importance of verifying the conclusions drawn as part of qualitative research. One of the main shortcomings in this study's methodology was the representativeness of the sample of local residents: all were involved to some degree in community activism, and the majority had in fact taken on leadership roles. Thus, their thoughts and experiences are unlikely to have been representative of the community as a whole. However, they were chosen as respondents due to their ability to provide informative answers to questions which less involved residents may not have been able to address. Unfortunately, this makes it difficult to generalise the conclusions drawn to other residents of Sobantu. 


\section{Further research}

It is very difficult to design a case study which is considered 'complete' on its own (Yin, 1994). Indeed, 2 recommendations for further research have come to light over the course of this study. The first relates to the narrow boundaries within which this research was conducted. It would be informative to explore the perspectives, interests, and possible involvement of stakeholders further upstream, primarily in the Northdale and Raisethorpe areas; though the Baynespruit joins the uMsunduzi at Sobantu, downstream communities may also be affected. Secondly, due to the nature of this study, it was difficult to get a true picture of the barriers and incentives to industrial pollution reduction. If selected companies agreed to take part in a more in-depth study, such as the one conducted by Bansal and Roth (2000) looking at firms in the UK and Japan, it would no doubt generate valuable insight.

\section{References}

ACUTT, N (2003) Perspectives on Corporate Social Responsibility: The South African Experience with Voluntary Initiatives. Centre for Social and Economic Research on the Global Environment, University of East Anglia, Norwich, U.K. URL: http://www.uea. ac.uk/env/cserge/pub/wp/ecm/ecm 2003 05.pdf (Accessed 6 June 2008).

AFSAH S, LAPLANTE B and WHEELER D (1997) Regulation in the Information Age: Indonesian Public Information Program for Environmental Management. URL: http://siteresources.worldbank. org/NIPRINT/Resources/RegulationInTheInformationAge.pdf. (Accessed 18 May 2008).

APPELSTRAND M (2002) Background paper on Public Participation and Collaboration. Paper prepared for the COST Action E19 meeting in Savonlinna, Finland, 5-6 April 2002.URL: http://www. metla.fi/eu/cost/e19/appelstrand.pdf (Accessed 11 June 2008).

ARNSTEIN S (1969) A Ladder of Citizen Participation. J. Am. Plann. Assoc. 35 (4) 216-224.

BANSAL P and ROTH K (2000) Why Companies Go Green: A Model of Ecological Responsiveness. Acad. Manage. J. 43 (4) 717-736.

BARRIBALL L and WHILE A (1994) Collecting data using a semistructured interview: a discussion paper. J. Adv. Nurs. 19 (2) 328.

BERKES F (2004) Rethinking community-based conservation. Conserv. Biol. 18 (3) 621-630.

BERKES F (2002) Cross-Scale Institutional Linkages: Perspectives from the Bottom Up. In: Ostrom E, Dietz T, Dolsak N, Stern P, Stonich S and Weber E (eds.) The Drama of the Commons. National Academy Press, Washington D.C. 293-321.

BORRINI-FEYERABEND G, PIMBERT M, FARVAR M, KOTHAR A and RENARD Y (2004) Chapter 2. Actors, entitlements, and equity in natural resource management. In: Sharing Power: Learning by doing in co-management of natural resources throughout the World. IIED and IUCN/ CEESP/ CMWG, Cenesta, Tehran. 37-63.

BURKE E (1968) Citizen participation strategies. J. Am. Plann. Assoc. 34 (5) 287-294.

BUYSSE K and VERBEKE A (2003) Proactive environmental strategies: A stakeholder management perspective. Strat. Manage. J. 24 (5) 453-470.

CARNES S, SCHWEITZER M, PEELLE E, WOLFE A and MUNRO $\mathrm{J}$ (1998) Measuring the success of public participation on environmental restoration and waste management activities in the U.S Department of Energy. Tech. Soc. 20 (4) 385-406.

DE CONING C and SHERWILL T (2004) An Assessment of the Water Policy Process in South Africa (1994 to 2003). WRC Report No. TT 232/04. Water Research Commission, Pretoria.URL: http:// www.wrc.org.za/downloads/report $\% 201$ ists/web\%20files/prepublication\%20TT232-04\%20final.pdf (Accessed 28 April 2008).

DWAF (DEPARTMENT OF WATER AFFAIRS AND FORESTRY, SOUTH AFRICA) (1996) South African Water Quality Guidelines
(Second Edition), Volume 2: Recreational Use. Department of Water Affairs and Forestry, Pretoria.

GAVENTA J (2004) Towards participatory governance: assessing the transformative possibilities. In: Hickey S and Mohan G (eds). Participation: From Tyranny to Transformation? Zed, London. 25-41.

GAVENTA J and VALDERRAMA C (1999) Participation, Citizenship and Local Governance. Background note prepared for workshop on 'Strengthening participation in local governance', June 21-24, 1999, Institute of Development Studies, University of Valencia, Spain. URL: http://www.uv.es/ fernandm/Gaventa,\%20Valderrama.pdf (Accessed 4 June 2008).

GLEW D, O'LEARY-KELLY A, GRIFFIN R and VAN FLEET D (1995) Participation in organizations: A preview of the issues and proposed framework for future analysis. J. Manage. 21 (3) 395-421.

GLOBAL WATER PARTNERSHIP (2000) Integrated Water Resources Management. Technical Advisory Committee (TAC) Background Papers No. 4.. URL: http://waterwiki.net/images/a/a5/ GWPIWRM.pdf (Accessed 17 May 2008).

GRIFFIN C (1999) Watershed councils: An emerging form of public participation in natural resource management. J. Am. Water. Resour. Assoc. 35 (3) 505-518.

HAMANN R and ACUTT N (2003) How should civil society (and the government) respond to 'corporate social responsibility'? A critique of business motivations and the potential for partnerships. Dev. S. Afr. 20 (2) 255-270.

HARDIN G (1968) The Tragedy of the Commons. Sci. 162 (3859) 1243-1248.

INVOLVE (2005) People \& participation - How to put citizens at the heart of decision-making. Beacon, Uckfield, U.K.URL: http:// www.involving.org/mt/archives/blog_13/People $\% 20$ and $\% 20$ Participation\%20final.pdf (Accessed 9 August 2008).

IRVIN R and STANSBURY J (2004) Citizen participation in decision making: Is it worth the effort? Publ. Admin. Rev. 64 (1) 55-65.

JONSSON A (2005) Public participation in water resources management: Stakeholder voices on degree, scale, potential, and methods in future water management. AMBIO 34 (7) 495-500.

KHANNA M (2001) Non-mandatory approaches to environmental protection. J. Econ. Surv. 15 (3) 291-324.

KLANDERMANS B and OEGEMA D (1987) Potentials, networks motivations, and barriers: Steps towards participation in social movements. Am. Socio. Rev. 52 (4) 519-531.

KPMG INTERNATIONAL (2008) KPMG International Survey of Corporate Responsibility Reporting 2008. KPMG LLP, U.K.

KRAEMER R, CHOUDHURY K and KAMPA E (2001) Protecting Water Resources: Pollution Prevention. Thematic Background Paper, Secretariat of the International Conference on Freshwater Bonn 2001.URL: http://www.cepis.ops-oms.org/bvsarg/i/fulltext/ pollution/pollution.pdf (Accessed 17 May 2008).

LOBER D (1998) Pollution prevention as corporate entrepreneurship. J. Organ. Change Manage. 11 (1) 26-37.

LOZARE B (1994) Power and conflict: hidden dimensions of communication, participative planning and action. In: White S, Nair S and Ascroft J (eds.) Participatory Communication: Working for Change and Development. Sage, London. 229-244.

MEADOWS D (1999) Leverage Points: Places to Intervene in a System. Sustainability Institute, Hartland, Vermont.

MOLLE F, MOLLINGA P and MEINZEN-DICK R (2008) Water, politics and development: Introducing Water Alternatives. Water Alternatives 1 (1) 1-6. URL: http://www.water-alternatives.org/ (Accessed 9 June 2008).

MONETTE D, SULLIVAN T and DEJONG C (2002) Applied Social Research: Tool for the Human Services (5th edn.) Harcourt, Orlando, Florida.

MSUNDUZI MUNICIPALITY (n.d.) Sobantu Community Profile. Area-Based Management, Msunduzi Municipality, Pietermaritzburg.

MULLEN M and ALLISON B (1999) Stakeholder involvement and social capital: keys to watershed management success in Alabama. J. Am. Water Resour. Assoc. 35 (3) 655-662.

NEGRA C (1998) Identifying Factors Leading to Effective Local Conservation Commissions. University of Vermont Extension, 
Burlington, VT, U.S.URL: http://www.caciwc.org/library/con com factors98.pdf (Accessed 4 June 2008).

PORTO M, LA LAINA PORTO R and AZEVEDO L (1999) A participatory approach to watershed management: The Brazilian system. J. Am. Water Resour. Assoc. 35 (3) 675-683.

PRESTBY J, WANDERSMAN A, FLORIN P, RICH R and CHAVIS D (1990) Benefits, costs, incentive management and participation in voluntary organizations: A means to understanding and promoting empowerment. Am. J. Community Psychol. 18 (1) 117-149.

RENN O, WEBLER T, RAKEL H, DIENEL P and JOHNSON B (1993) Public participation in decision making: A three-step procedure. Pol. Sci. 26 (3) 189-214.

SENGE P, SCHARMER O, JAWORSKI J and FLOWERS B (2005) Presence: An Exploration of Profound Change in People, Organizations, and Society. Nicholas Brealey, London.

SENGE P, SMITH B, KRUSCHWITZ N, LAUR J and SCHLEY S (2008) The Necessary Revolution: How Individuals and Organizations are Working Together to Create a Sustainable World. Nicholas Brealey, London.

SERVAES J and ARNST R (1999) Principles of Participatory Communication Research: Its Strengths (!) and Weaknesses (?). In: Jacobsen T and Servaes J (eds.) Theoretical Approaches to Participatory Communication. Hampton, Cresskill, New Jersey. 107-130.

STATISTICS SA (2001) Statistics South Africa: Census 2001. URL: http://www.statssa.gov.za/census2001/atlas_ward/index.html (Accessed 1 October 2008).

TERRY S (2008) Personal communication, 16 May 2008. Water Quality Scientist, Umgeni Water, PO Box 9 Pietermaritzburg, 3200

THOMPSON H, STIMIE C, RICHTERS E and PERRET S (2001) Policies, legislation and organizations related to water in South Africa, with special reference to the Olifants river basin. Working Paper 18 (South Africa Working Paper No. 7). International Water
Management Institute, Colombo, Sri Lanka. URL: http://www. iwmi.cgiar.org/assessment/files_new/research_projects/River Basin_Development and Management/WPaper18.pdf (Accessed 28 April 2008).

TRIANA E and ORTOLANO L (2005) Influence of organizational learning on water pollution control in Colombia's Cauca Valley. Int. J. Water Resour. Dev. 21 (3) 493-508.

UMGENI WATER (2002) Annual Sustainability Report 2001-2002. Umgeni Water, Pietermaritzburg.

UMGENI WATER (2008) River monitoring data (Unpublished). Umgeni Water, Pietermaritzburg.

WANDERSMAN A, FLORIN P, FRIEDMANN R and MEIER R (1987) Who participates, who does not, and why? An analysis of voluntary neighborhood organizations in the United States and Israel. Sociol. Forum 2 (3) 534-555.

WANG H, BI J, WHEELER D, WANG J, CAO D, LU G and WANG Y (2004) Environmental performance rating and disclosure: China's GreenWatch program. J. Environ. Manage. 71 (2) 123-133.

WARNER J (2006) More sustainable participation? Multi-stakeholder platforms for integrated catchment management. Int. J. Water Resour. Dev. 22 (1) 15-35.

WHEELER D (1999) Greening Industry: New Roles for Communities, Markets and Governments. Oxford University Press / World Bank, New York. URL: http://econ.worldbank.org/external/default/main ?pagePK=64165259\&theSitePK=469372\&piPK=64165421\&menuP $\underline{\mathrm{K}=64166093 \& \text { entityID }=000094946 \quad 9911240530591}$ (Accessed 23 August 2008).

WIDMER C (1989) Why board members participate. In: Herman R and Van Til J (eds.) Nonprofit Boards of Directors: Analyses and Applications. Transaction, New Brunswick, US. 8-23.

YIN R (1994) Case Study Research: Design and Methods. Applied Social Research Methods Series, Volume 5 (2nd edn.). Sage, London. 
Available on website http://www.wrc.org.za ISSN 0378-4738 (Print) = Water SA Vol. 36 No. 5 October 2010 